International Journal of Plant \& Soil Science
10(5): 1-12, 2016; Article no.IJPSS.25205
ISSN: 2320-7035
of Plenut \& Soil Science
SCIENCEDOMAIN international
www.sciencedomain.org

\title{
Quality and Quantity of Organic Fractions as Affected by Soil Depth in an Argiudoll under Till and No-till Systems
}

\author{
Juan A. Galantini ${ }^{1 *}$, Matias Duval ${ }^{2}$, Juan M. Martinez ${ }^{2}$, Verónica Mora ${ }^{2}$, \\ Roberto Baigorri ${ }^{3}$ and José M. García-Mina ${ }^{3,4}$ \\ ${ }^{1}$ Comisión Investigaciones Científicas (CIC); CERZOS - Departamento de Agronomía, \\ San Andrés 800, 8000 Bahía Blanca, Argentina. \\ ${ }^{2}$ CONICET, CERZOS - Departamento de Agronomía, UNS, Argentina. \\ ${ }^{3}$ CIPAV-R\&D Roullier Group. Polígono Arazuri-Orcoyen, 31160 Orcoyen, Spain. \\ ${ }^{4}$ Department of Chemistry and Soil Chemistry, Faculty of Sciences, University of Navarra, Spain.
}

\section{Authors' contributions}

This work was carried out in collaboration between all authors. Author JAG designed the study, performed the statistical analysis, wrote the protocol and wrote the first draft of the manuscript. Authors MD and JMM managed the soil sampling and the chemical analyses of the study. Authors VM and RB managed the FT-IR analyses. Author JMGM managed quality of humic substances interpretation. All authors read and approved the final manuscript.

Article Information

DOI: $10.9734 /$ IJPSS/2016/25205 Editor(s):

(1) Wael Kawy, Professor of Soil Science, Department of Soil Science, Faculty of Agriculture, Cairo University, Giza, Egypt. Reviewers:

(1) Akhmad Saidy, Lambung Mangkurat University, Indonesia. (2) Evans Ntim Amedor, Kumasi Institute of Tropical Agriculture, Ghana. (3) Fabio Henrique Portella Correa de Oliveira, Laboratorio de Hidrobiologia, Rua Dois Irmaos, Brazil. Complete Peer review History: http://sciencedomain.org/review-history/14142

Original Research Article

Received $23^{\text {rd }}$ February 2016

Accepted $4^{\text {th }}$ April 2016

Published $12^{\text {th }}$ April 2016

ABSTRACT

Aims: The aim of this study was to evaluate the long-term effect of tillage systems on the quantity and quality of organic carbon fractions at different soil layers.

Study Design: The experimental design was a split plot with three blocks. The long-term effects (25 years) of conventional- (CT) and no-tillage (NT) systems on a Tipic Argiudoll was sampled at 0 5, 5-10, 10-15 and 15-20 cm soil depth.

Place and Duration of Study: The field experiment was carried out at Tornquist $\left(38^{\circ} 07^{\prime} 06^{\prime \prime} \mathrm{S}-\right.$

*Corresponding author: E-mail: juangalantini@gmail.com; 
$62^{\circ}$ 02' 17" O) and soil sampling was performed during wheat seeding (June 2011).

Methodology: Total soil organic carbon (SOC) content and the following fractions were determined: Coarse particulate $\left(\mathrm{POC}_{c}, 105-2000 \mu \mathrm{m}\right)$, fine particulate $\left(\mathrm{POC}_{\mathrm{f}}, 53-105 \mu \mathrm{m}\right)$ and mineral-associated (MOC, 0-53 $\mu \mathrm{m}$ ) carbon fractions; humic (HA) and fulvic (FA) acids; and total $\left(\mathrm{CH}_{t}\right)$ and soluble $\left(\mathrm{CH}_{\mathrm{s}}\right)$ carbohydrates. The main physico-chemical properties of $\mathrm{HA}$ and FA were analyzed using both FT-IR and fluorescence spectroscopies.

Results: After 25 years, total SOC at the $0-20 \mathrm{~cm}$ depth was $9 \%$ higher in no-tilled than in tilled soils. The $\mathrm{POC}_{f}$ was the $\mathrm{SOM}$ fraction that turned out to be the most sensitive to tillage effects. The $\mathrm{POC}_{\mathrm{c}}: \mathrm{POC}_{\mathrm{f}}: \mathrm{MOC}$ ratio at $0-20 \mathrm{~cm}$ was similar for NT $(3: 14: 82)$ and $\mathrm{CT}(5: 10: 84)$; however, differences were found across soil depths. Tilled soils showed higher aromaticity, starting by $\mathrm{CH}$ degradation, in more superficial soil layers.

Conclusion: The no-tillage system presented a different pattern which can be related to distribution of crop residues and conditions for humification along the soil depth.

Keywords: Tillage system; soil organic carbon; chemical and physical fractionation.

\section{ABBREVIATIONS}

\begin{tabular}{|c|c|}
\hline $\mathrm{CHs}$ & : Soluble carbohydrates \\
\hline $\mathrm{CHt}$ & : Total carbohydrates \\
\hline$C T$ & : Conventional tillage \\
\hline E4/E6 & $\begin{array}{l}\text { The ratio of optical densities or absorbances of dilute, aqueous humic } \\
\text { and fulvic acid solutions at } 465 \text { and } 665 \mathrm{~nm}\end{array}$ \\
\hline$F A$ & : Fulvic acid \\
\hline$F A-C$ & : Carbon content in the fulvic acid \\
\hline$H A$ & : Humic acid \\
\hline IHSS & : International Humic Substances Society \\
\hline MOC & : Mineral associated organic carbon \\
\hline NT & : No-tillage \\
\hline POC & : Particulate organic carbon \\
\hline$P O C C$ & : Coarse particulate organic carbon $(105-2000 \mu \mathrm{m})$ \\
\hline POCf & : Fine particulate organic carbon (53-105 $\mu \mathrm{m})$ \\
\hline POM & : Particulate organic matter \\
\hline SOC & : Soil organic carbon \\
\hline SOM & : Soil organic matte \\
\hline
\end{tabular}

\section{INTRODUCTION}

Soil organic matter (SOM) plays a key role in several processes of the soil ecosystem, including soil structure formation, water retention, detoxification of anthropogenic chemicals, carbon sequestration, nutrient cycling, and energy supply to soil microorganisms. It is made up of compounds with diverse biochemical properties and varying degrees of association to the mineral matrix, which differentially contribute to the overall dynamics of SOM and its properties. These organic compounds are a continuum of materials whose cycling rate ranges from weeks to millennia [1]. This continuum can be conceptually divided into discrete kinetic pools, which are of special interest to researchers, since SOM characterization is a key contribution to their studies.
A large number of SOM fractionation and characterization techniques have been developed to gain an insight into the stabilization and destabilization mechanisms that underlie SOM dynamics in the short and long term $[2,3,4,5]$. Numerous fractionation schemes have been devised with the purpose of separating 'functional' SOM fractions that are more homogeneous in terms of their biochemical properties and turnover times [6,7]. Such techniques also attempt to identify SOM fractions that respond more rapidly to management or land use changes and may thus serve as early indicators of soil quality or health $[8,9]$. For over two centuries of research, SOM fractions were extracted mainly by chemical methods, which were dominant until recent decades $[10,11,12]$; since then, physical extractions have become increasingly popular, and more elaborate analyses for microbial characteristics have been 
developed [13]. Chemical extractions are used for the advanced characterization of SOM, to study the interaction between humic substances and metals or agrochemicals, and to assess decomposition of organic materials; however, they have not been linked to physically extracted SOM fractions, which are commonly used to isolate discrete pools with different dynamics. Physical extraction methods are based on the premise that the association of soil minerals with organic matter, as well as their three-dimensional architecture, is responsible for SOM dynamics and stability [14]. It is well-known that particulate organic matter (POM) is more sensitive in detecting short-term changes than mineral associated organic matter (MOM). However, POM content can be modified by weather conditions or crop cycles [15] and hence the separation of SOM in different sand sizes can help to distinguish time-weather variability from management variability $[16,17]$.

Most studies used to apply only one type of extraction procedure, i.e. either chemical or physical separation. Nevertheless, the effects of cropping practices can be better understood if both methods are combined [15]. Management practices may modify SOM content -or soil organic carbon (SOC), its main component- as a result of changes in SOM decomposition, of residue input, or both [18]. Reducing tillage intensity has been widely recognized as a successful strategy to minimize SOC losses $[19,20,21]$.

Soils in semiarid and subhumid regions are characterized by a poor SOM content [22]. In these areas, the high demand of evapotranspiration cannot be met by the scanty and erratic rainfalls; as a result, crop biomass production tends to be low, with a limited Carbon input into the soil. Under these conditions, the dynamics of SOM fractions will be more strongly affected by water availability [23]. Tillage practices accelerate SOM decomposition and soil $\mathrm{C}$ loss to the atmosphere as $\mathrm{CO}_{2}$. Mixing residue and soil favors physical contact with soil microorganisms, creates optimal soil microclimatic conditions (e.g. temperature and aeration) for crop residue decomposition [24] and changes carbon input location.

Over the last few years, no-tillage (NT) has become a popular conservation practice in Argentina, and it has been expanding at a steady pace since the early 1990s. At present, the total area under NT is estimated at 27 million ha, which accounts for over 80 percent of the total annually cropped area [25].

For this reason, information about the long-term effects on soil organic fractions is scarce, notably in studies which combine both chemical and physical extraction methods. Moreover, the transformation and stabilization processes in the upper soil layers can be modified by differences in carbon input and soil moisture linked to tillage system. These changes, though, may go undetected when the A-horizon or the $0-20 \mathrm{~cm}$ layer are sampled as a whole.

Our hypothesis is that under different tillage systems soil moisture and carbon input change both the quantity and quality of labile soil organic fractions at different depth levels.

The objective of this study was to evaluate the effect of 25 years of tillage (conventional tillage and no-tillage) on the quantity and quality of physically and chemically separated soil organic carbon fractions, and to determine the main physico-chemical changes of humic substances at different soil depths.

\section{MATERIALS AND METHODS}

\subsection{Site Description and Sampling}

The field experiment was carried out on a loamy

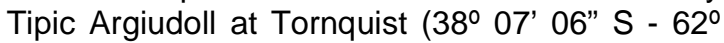
02 ' 17" O), SW of Buenos Aires province, Argentina. The mean annual temperature in this area is $15^{\circ} \mathrm{C}$ and the average precipitation is 735 $\mathrm{mm}$ (1887-2012).

The tillage systems used in the experiment were the conventional type (CT), with chisel and disk harrow, and no-tillage (NT), with chemical weed control. The experimental design was a split plot with three blocks of $27 \times 20$ m each.

The full crop sequence was: M-W-S-W-S-W-SoB-M-B-M-W-M-W-B-S-W-W-S-B-S-W-M

(grazing)-W (no harvest due to severe drought)W and W, where: M, maize (Zea mays L.); W, wheat (Triticum aestivum L.); S, sunflower (Helianthus annuus L.); B, barley (Hordeum vulgare L.); and So, sorghum (Sorghum bicolor L. Moench).

The soil sampling was performed in 2011, at wheat emergence (July). Three composite samples (five subsamples) were collected in each block and treatment at $0-5,5-10,10-15$ and $15-20 \mathrm{~cm}$ depths. The $0-20 \mathrm{~cm}$ values were calculated from these depths. 
The samples were air-dried, crushed and passed through a 2-mm aperture sieve.

\subsection{Chemical and Spectrometric Determinations}

Total soil organic carbon (SOC) was determined by dry combustion (LECO Carbon analyzer, LECO Corporation St. Joseph, MI, USA).

Extraction of carbohydrates was performed employing two different procedures [26,27]: Total carbohydrates $(\mathrm{CHt})$ extraction was performed by an acid hydrolysis as follow: $1 \mathrm{~g}$ of soil sample was treated with $10 \mathrm{~mL}$ de $\mathrm{H}_{2} \mathrm{SO}_{4} 0.5 \mathrm{M}$, heated at $80^{\circ} \mathrm{C}$ for $24 \mathrm{~h}$. Soluble carbohydrates $(\mathrm{CHs})$ extraction was carried out as follow: $1 \mathrm{~g}$ of soil sample was suspended in $10 \mathrm{~mL}$ of distilled water and heated at $80^{\circ} \mathrm{C}$ for $24 \mathrm{~h}$, and hydrolysis was attained by adding $\mathrm{H}_{2} \mathrm{SO}_{4}$ to obtain a $0.5 \mathrm{M}$ concentration as in the dilute acid hydrolysis procedure.

Soil organic matter fractions were separated by size using a wet-sieving method $[6,16]$. Briefly, $50 \mathrm{~g}$ of air-dried sieved $(2 \mathrm{~mm})$ soil and $100 \mathrm{~mL}$ of distilled water were placed in $120 \mathrm{~mL}$ glass containers. Also, ten glass beads were added to increase fragmentation and reduce potential problems created by different sand contents [28]. The samples were subjected to mechanical dispersion on a rotary shaker for approximately 16 hours (overnight) to disintegrate the aggregates. The sieving was done with a pair of 270- and 140-mesh sieves (53 and $105 \mu \mathrm{m}$, respectively), which moved back and forth until the water passing through them was reasonably clear. Three fractions were obtained: i) a coarse fraction $(105-2000 \mu \mathrm{m})$ containing particulate organic matter (POM) and fine + medium + coarse sands; ii) a medium fraction (53-105 $\mu \mathrm{m})$ with the most transformed POM and very fine sand; iii) a fine fraction $(<53 \mu \mathrm{m})$ which includes mineral-associated organic matter (MOM) and silt + clay minerals. The material retained in each sieve was dried, homogenized and analyzed for $\mathrm{C}$ so as to obtain coarse particulate (POCc), fine particulate (POCf) and mineral-associated organic carbon (MOC) contents in the 105-2000, 53-105 and 0-53 $\mu \mathrm{m}$ size fractions, respectively. The POCc:POCf:MOC ratio was calculated as the percentage of each fraction of total soil organic carbon.

The isolation of humic acid (HA) was carried out following the standard International Humic Substances Society (IHSS) procedure [29]. To avoid HA contamination with labile organic matter, the soil fine fraction $(0-53 \mu \mathrm{m}$, obtained from physical fractionation procedure) was used for HA isolation. The main physico-chemical properties of HA were analyzed using both FT-IR and Fluorescence spectroscopy, as described by Baigorri et al. [30].

The E4/E6 ratio in HA was determined according to the method outlined by Chen et al. [31]. The measurements of E4/E6 in FA solution were performed directly without lyophilization. Soil $\mathrm{pH}$ was adjusted to 7 and FA concentration was maintained at $0.01-0.05 \%$; the carbon content in the fulvic acid (FA-C) was estimated by UVabsorbance at $410 \mathrm{~nm}$ [32].

For fluorescence measurements, solutions of 10 ppm organic carbon were prepared in $0.05 \mathrm{M}$ $\mathrm{NaHCO}_{3}$. All spectra analyses were performed on a Perkin Elmer LS50B fluorescence spectrophotometer, with a scan speed set at 300 $\mathrm{nm} \mathrm{min}^{-1}$, and excitation and emission slit bandwidths at $7 \mathrm{~nm}$.

For the FT-IR study, pellets were prepared by mixing $1 \mathrm{mg}$ of each freeze-dried sample with $100 \mathrm{mg}$ of $\mathrm{KBr}$ so that the mixture became homogeneous. Infrared spectra were recorded on these pellets with a Nicolet Magna-IR 550 spectrometer over the $4000-400 \mathrm{~cm}^{-1}$ range.

\subsection{Statiscal Analysis}

The difference in the results between treatments were tested by two-way ANOVA (depth and tillage systems as variables) using Fisher's LSD mean separation test at $p<0.05$. The data were analyzed by the ANOVA procedure with the InfoStat statistical software [33].

\section{RESULTS AND DISCUSSION}

\subsection{Total Soil Organic Carbon and Physically Separated Fractions}

Total SOC concentration in the $0-20 \mathrm{~cm}$ depth was $9 \%$ higher under NT than under CT, chiefly because of a higher concentration in both the upper and lower analyzed layers (Table 1). This difference can be larger when the comparison is made on an equivalent soil mass [34]. However, the assumption that there was no soil loss by tillage did not apply in this case. Previous studies found higher soil losses under CT as compared with NT [23], which was attributed to soil erosion.

Residue incorporation into the tillage depths (510 and $10-15 \mathrm{~cm}$ ) brought about no differences 
in total SOC under CT as compared with NT. Soil organic fractions revealed varying degrees of sensitivity to the tillage systems. The POCc did not present any differences between tillage systems at $0-20 \mathrm{~cm}$; however, a significant increase was observed at the $5-10 \mathrm{~cm}$ depth under CT as a consequence of residue incorporation. The coarse particulate fraction can show a faster dynamics and higher sensitivity to weather conditions than the fine particulate fraction $[16,35]$. The POCf fraction at the $0-20 \mathrm{~cm}$ depth was higher under NT than under CT, and this difference was found in all analyzed layers. This SOM fraction was sensitive to management practices, as found in other studies [16]. The most transformed fraction, MOC, was significantly higher at the $0-20 \mathrm{~cm}$ depth under NT, primarily as a result of a MOC increase in the upper layer $(0-5 \mathrm{~cm})$. Crop residues on the soil surface enhanced carbon input and wet conditions favored its humification.

Taking into account that transformation of soil organic materials follows the POCc - POCf MOC sequence $[17,35]$, the relationship among these organic fractions can be used as an indicator of SOC dynamics (Table 1). In NT, the POCc:POCf:MOC ratio showed a slow increase of humified compounds with depth. This can be explained because the largest carbon input, above-ground dry matter, was maintained on the soil surface and because soil water conservation improved the humification process of root dry matter. This ratio, however, indicated two different trends under CT. The upper layers (0-5 and 5-10 cm) contained largely the less transformed fractions, whereas the lower layers included mainly the most transformed SOM.

Tillage dramatically affect soil surface moisture, reducing water infiltration (soil crusts) and increasing runoff, while low residue cover enhance soil water evaporation $[36,37]$. The crop residue cover was lost faster under CT than under NT. At seeding time, the residue cover was $12 \%$ under CT and $86 \%$ under NT.

\subsection{Chemically Separated Fractions}

Humic substances showed a significant tillage $x$ depth interaction, indicating a different behavior of HS across soil layers (Table 2). In terms of carbon concentration, FA-C levels were found to be similar for both tillage systems, whereas HA-C values were higher and Hum-C lower under NT in comparison with $\mathrm{CT}$.
Carbon accumulation in the humin fraction suggests a decrease in labile organic matter fractions in relation to resistant or recalcitrant ones, probably as a consequence of till activity [38]. Under this condition, soil nutrients can cycle faster in NT, thereby improving nutrient availability to crops, particularly soil nitrogen. The most pronounced difference was found in the upper 0-5 cm layer under NT; on the other hand, differences along depths under CT were slight as a result of soil mixing by tillage. Surface residue accumulation increased concentration of FA at 0 $5 \mathrm{~cm}$, and of $\mathrm{HA}$ at $0-5$ and $5-10 \mathrm{~cm}$.

The E4/E6 ratio of HA showed similar values under both tillage systems and across soil depths, indicating analogous characteristics of soil $H A$. The E4/E6 ratio of $F A$ at the $0-20 \mathrm{~cm}$ depth was similar for both tillage systems; however, the depth of crop residue incorporation seemed to modify the characteristics of FA $[31,39]$. The E4/E6 ratio of FA extracted from the layer with residue incorporation, $0-5 \mathrm{~cm}$ under NT, and 5-10 and $10-15 \mathrm{~cm}$ under CT, was higher than in the other layers.

These results followed the same trend as the physically separated size fractions, and they suggest that the humification process was highly sensitive to soil environmental conditions and substrate incorporation at each layer level; the depth changes may go unnoticed when the Ahorizon or the $0-20 \mathrm{~cm}$ layer are sampled as a whole.

Concentration of $\mathrm{CHt}$ and $\mathrm{CH}$ showed different distribution patterns between tillage systems (Fig. 1). In no-tillage, $\mathrm{CHt}$ concentration was lower at $0-5 \mathrm{~cm}$ than in deeper soil layers (5-10, $10-15$ and $15-20 \mathrm{~cm}$ ). Even if the residue input under NT was located at $0-5 \mathrm{~cm}$, the lower $\mathrm{CHt}$ concentration can be related to the slow decomposition of surface residues.

In conventional tillage, $\mathrm{CHt}$ concentration was lower in the upper layers (0-5, 5-10 and 10-15 $\mathrm{cm})$ than in deeper layers $(15-20 \mathrm{~cm})$. Residue incorporation through tillage and the higher bulk density at $15-20 \mathrm{~cm}$ may account for the accumulation of undecomposed plant materials. The content of $\mathrm{CHt}$ in NT soils was higher at 5-10 and $10-15 \mathrm{~cm}(\mathrm{P}<0.01)$, slightly high at $0-5 \mathrm{~cm}$ $(P<0.05)$ and no differences were found at $15-20$ $\mathrm{cm}$ in comparison with $\mathrm{CT}$. Higher $\mathrm{CHs}$ concentration was found only on the soil surface under NT, and no differences were observed for the others depths. 

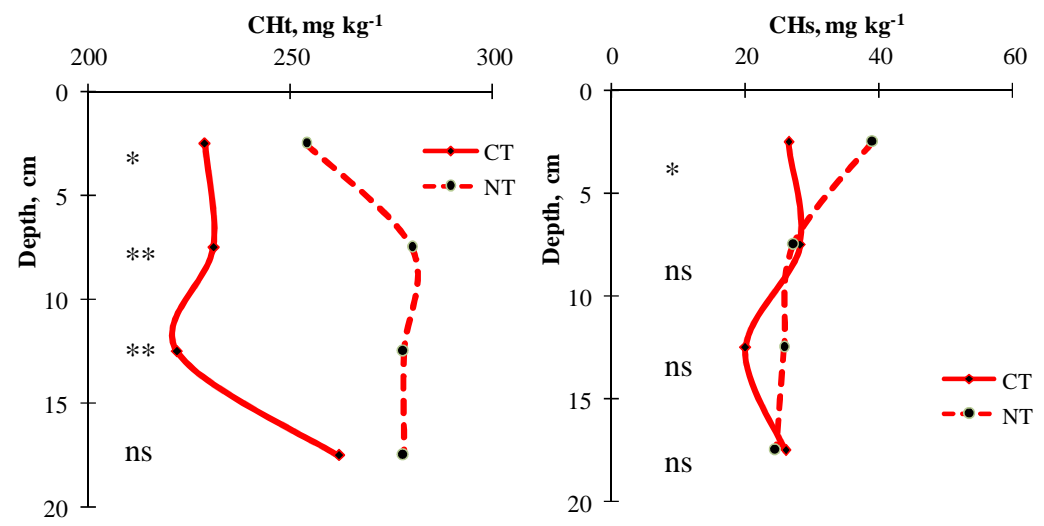

Fig. 1. Total (CHt) and soluble (CHs) carbohydrates under two tillage systems

\subsection{Quality of Humic and Fulvic Acids}

With regard to the pattern of variation caused by tillage practices (CT or NT) for the HA from each soil depth, FT-IR results failed to show apparently, at least- noticeable differences; yet the study of changes in the main functionalrelated bands provided relevant information (Fig. 2). As expected, the variation patterns of the $\mathrm{CH}$ related band $\left(1030 \mathrm{~cm}^{-1}\right)$ revealed that tillage favored a rapid degradation of carbohydrates $(\mathrm{CH})$ when compared with the NT system. While CT showed low bands for the 0-5, 5-10 and 10$15 \mathrm{~cm}$ depths, NT did so only at $0-5 \mathrm{~cm}$. In principle, assuming that crop residues are homogenized with soil material in depth thanks to tillage practices, the results obtained can be interpreted as the consequence of different degrees of humification (mainly the activity of aerobic microorganisms) at each soil depth. In the case of NT, however, this result might also be influenced by a natural selection (size, composition, biological activity, etc.) of the organic material that may move down in the soil matrix with depth. This different degree of degradation was also reflected in aromaticrelated bands $\left(1610\right.$ and $\left.1310 \mathrm{~cm}^{-1}\right)$. In the CT system, these bands were higher at 0-5 and 5-10 $\mathrm{cm}$ than at 10-15 and $15-20 \mathrm{~cm}$. This outcome was in line with the one obtained for $\mathrm{CH}$, since the humification process is normally related to an increase in aromaticity $[40,41]$. The results were more difficult to interpret in the NT system, though. They indicated that aromaticity was higher at $0-5 \mathrm{~cm}$ than at $5-10 \mathrm{~cm}$. This might be explained by an increase in humification at these depths [42].

Aromaticity was high both for the 10-15 and 15$20 \mathrm{~cm}$ depths, even higher than for $0-5 \mathrm{~cm}$.
These results did not coincide with those obtained for $\mathrm{CH}$ in the context of different humification degrees across depths. In fact, they were more consistent with the above-proposed natural selection of organic material across soil depths. This explanation can also account for the variation patterns of carboxylic-related bands (1710 and $1250 \mathrm{~cm}^{-1}$ ), since they indicated a high correlation with those of aromaticity (Fig. 2). Regarding aliphaticity, the marker-band (2940 $\mathrm{cm}^{-1}$ ) did not show clear trends.

Finally, the pattern of changes for the total-OH band $\left(3390 \mathrm{~cm}^{-1}\right)$ revealed that the relative abundance of $\mathrm{OH}$ in carboxylic groups under CT seemed to be rather low when compared with those under NT.

All these results were confirmed from the Fluorescence study (Fig. 3). It showed that the HA from deeper soil layers under CT had a slight peak shift to higher wavelengths, indicating an increase in the aromaticity and complexity of their molecular structure; these characteristics can be associated with higher humification under superficial soil layers [43]. In this conceptual framework, a higher humification was observed for the HA under CT when compared with NTHA, except for the 15-20 cm depth (Fig. 3).

The characteristics of FA were modified by the depth of residue input. Under NT, the highest peak intensity occurred in the surface layer, where crop residue was accumulated and slowly decomposed at a rate that depended on weather conditions. The lowest peak intensity was observed in the FA from the following soil layers, where water availability favored microbial activity.

The FT-IR spectra of FA from the surface soil showed higher peaks in the $3445 \mathrm{~cm}^{-1}$ region $(\mathrm{H}$ - 
bonded $\mathrm{OH}$, free $\mathrm{OH}$, intermolecular bonded $\mathrm{OH}$ ) and the $1400 \mathrm{~cm}^{-1}$ region (aliphatic $\mathrm{C}-\mathrm{H}$ deformation), which indicated less transformed material. This can occur as a consequence of a high residue input and a lower decomposition rate. The FT-IR spectra showed a peak increase with depth in the vicinity of $1631 \mathrm{~cm}^{-1}(\mathrm{C}=\mathrm{C}$ stretching vibration of double bonds of cyclic and acyclic compounds); this is an evidence of a higher transformation process which was also indicated by the E4/E6 ratio. An opposite trend was observed under CT. The upper layer showed slighter intensity peaks as a consequence of a lower residue input and a faster decomposition rate, in comparison with the 5-10 and 10-15 cm layers, where the largest residue amount was incorporated through tillage. FT-IR of FA from the deepest layer, $15-20 \mathrm{~cm}$, revealed similar characteristics under both tillage systems, suggesting a different humification dynamics of crop residues in the upper $15 \mathrm{~cm}$ of soil.

Table 1. Soil organic carbon (SOC), coarse (POCc) and fine (POCf) particulate organic carbon, and mineral-associated organic carbon (MOC) under two tillage systems

\begin{tabular}{|c|c|c|c|c|c|}
\hline & SOC & $\mathbf{P O C}_{\mathrm{c}}$ & $\mathrm{POC}_{\mathrm{f}}$ & MOC & $\mathrm{POC}_{\mathrm{c}}: \mathrm{POC}_{\mathrm{f}}: \mathrm{MOC}$ \\
\hline NT & $\%$ & & & & Ratio \\
\hline $0-5$ & $2.18^{* *}$ & $0.15^{\mathrm{ns}}$ & $0.35^{* *}$ & $1.69^{* *}$ & $6: 16: 77$ \\
\hline $5-10$ & $1.72^{\mathrm{ns}}$ & $0.04^{* *}$ & $0.26^{* *}$ & $1.42^{\text {ns }}$ & $2: 15: 82$ \\
\hline $10-15$ & $1.56^{\text {ns }}$ & $0.03^{\text {ns }}$ & $0.22^{* *}$ & $1.32^{\text {ns }}$ & $1: 14: 84$ \\
\hline $15-20$ & $1.52^{*}$ & $0.02^{\text {ns }}$ & $0.22^{* *}$ & $1.28^{\text {ns }}$ & $1: 14: 84$ \\
\hline $0-20$ & $1.75^{* \star}$ & $0.06^{\text {ns }}$ & $0.26^{* *}$ & $1.42^{* *}$ & $3: 14: 82$ \\
\hline \multicolumn{6}{|l|}{ CT } \\
\hline $0-5$ & 1.74 & 0.18 & 0.20 & 1.36 & $10: 11: 78$ \\
\hline $5-10$ & 1.72 & 0.17 & 0.19 & 1.36 & $9: 11: 79$ \\
\hline $10-15$ & 1.55 & 0.02 & 0.14 & 1.39 & $1: 9: 89$ \\
\hline $15-20$ & 1.42 & 0.02 & 0.13 & 1.27 & $1: 9: 89$ \\
\hline $0-20$ & 1.61 & 0.10 & 0.16 & 1.34 & $5: 10: 84$ \\
\hline Tillage & $* *$ & ** & $* *$ & * & \\
\hline Depth & ** & ** & ** & * & \\
\hline Interaction & ** & ** & ** & * & \\
\hline
\end{tabular}

SOC, Total soil organic carbon; POCc, coarse particulate organic carbon (105-2000 $\mu \mathrm{m}) ;$ POCf, fine particulate organic carbon (53-105 $\mu \mathrm{m})$; MOC, mineral-associated organic carbon (0-53 $\mu \mathrm{m})$. NT, no-tillage; CT, conventional tillage, For each carbon fraction and depth, **, *, ns, differences at 0.01, 0.05 and no significant difference between tillage systems

Table 2. Carbon content (\%) in fulvic acid (FA-C), humic acid (HA-C) and humin (Hum-C) and the E4/E6 ratio in FA and HA from an Argiudoll under two tillage systems

\begin{tabular}{|c|c|c|c|c|c|}
\hline & FA-C & HA-C & Hum-C & $E_{4} / E_{6}$ & \\
\hline NT & & & & FA & HA \\
\hline $0-5$ & $0.24^{\underline{a}^{* *}}$ & $0.64^{\mathrm{a}^{\text {** }}}$ & $0.82^{\text {ans }}$ & $17.0^{\mathrm{a}}$ & $7.3^{\mathrm{a}}{ }^{* \star}$ \\
\hline $5-10$ & $0.20^{b}$ * & $0.61^{\mathrm{a}}{ }^{* *}$ & $0.61^{b *}$ & $9.8^{b \text { * }}$ & $6.8^{\mathrm{ab} \mathrm{ns}}$ \\
\hline $10-15$ & $0.20^{b * *}$ & $0.40 b^{n s}$ & $0.72^{\mathrm{ab} *}$ & $8.4^{\mathrm{b} n s}$ & $5.9^{\mathrm{bns}}$ \\
\hline $15-20$ & $0.18^{\mathrm{c} \mathrm{ns}}$ & $0.41^{\mathrm{bns}}$ & $0.69^{a b n s}$ & $8.5^{\mathrm{b} \mathrm{ns}}$ & $5.8^{\mathrm{b} n s}$ \\
\hline $0-20$ & $0.20^{\mathrm{ns}}$ & $0.51^{* *}$ & 0.71 & $10.9^{\mathrm{ns}}$ & $6.5^{\mathrm{ns}}$ \\
\hline \multicolumn{6}{|l|}{$\mathbf{C T}$} \\
\hline $0-5$ & $0.19^{a}$ & $0.34^{\underline{a}}$ & 0.83 & $9.1^{b}$ & $5.8^{\underline{a}}$ \\
\hline $5-10$ & $0.18^{\mathrm{ab}}$ & $0.35^{\mathrm{a}}$ & 0.83 & $12.7^{\mathrm{a}}$ & $6.9^{a}$ \\
\hline $10-15$ & $0.17^{b}$ & $0.37^{a}$ & 0.85 & $13.3^{\mathrm{a}}$ & $6.8^{\mathrm{a}}$ \\
\hline $15-20$ & $0.17^{b}$ & $0.38^{a}$ & 0.71 & $6.9^{\mathrm{b}}$ & $5.9^{a}$ \\
\hline $0-20$ & 0.18 & 0.36 & 0.81 & 10.5 & 6.4 \\
\hline Tillage & ** & * & * & * & * \\
\hline Depth & $* *$ & * & * & ** & * \\
\hline Interaction & * & ** & $\star *$ & * & $\star *$ \\
\hline
\end{tabular}

Within each carbon fraction and tillage system, means followed by the same letters are not significantly different at $P<$ 0.05 , For each carbon fraction and depth, ${ }^{* *},{ }^{*}, n s$, differences at $0.01,0.05$ and no significant difference between tillage systems 


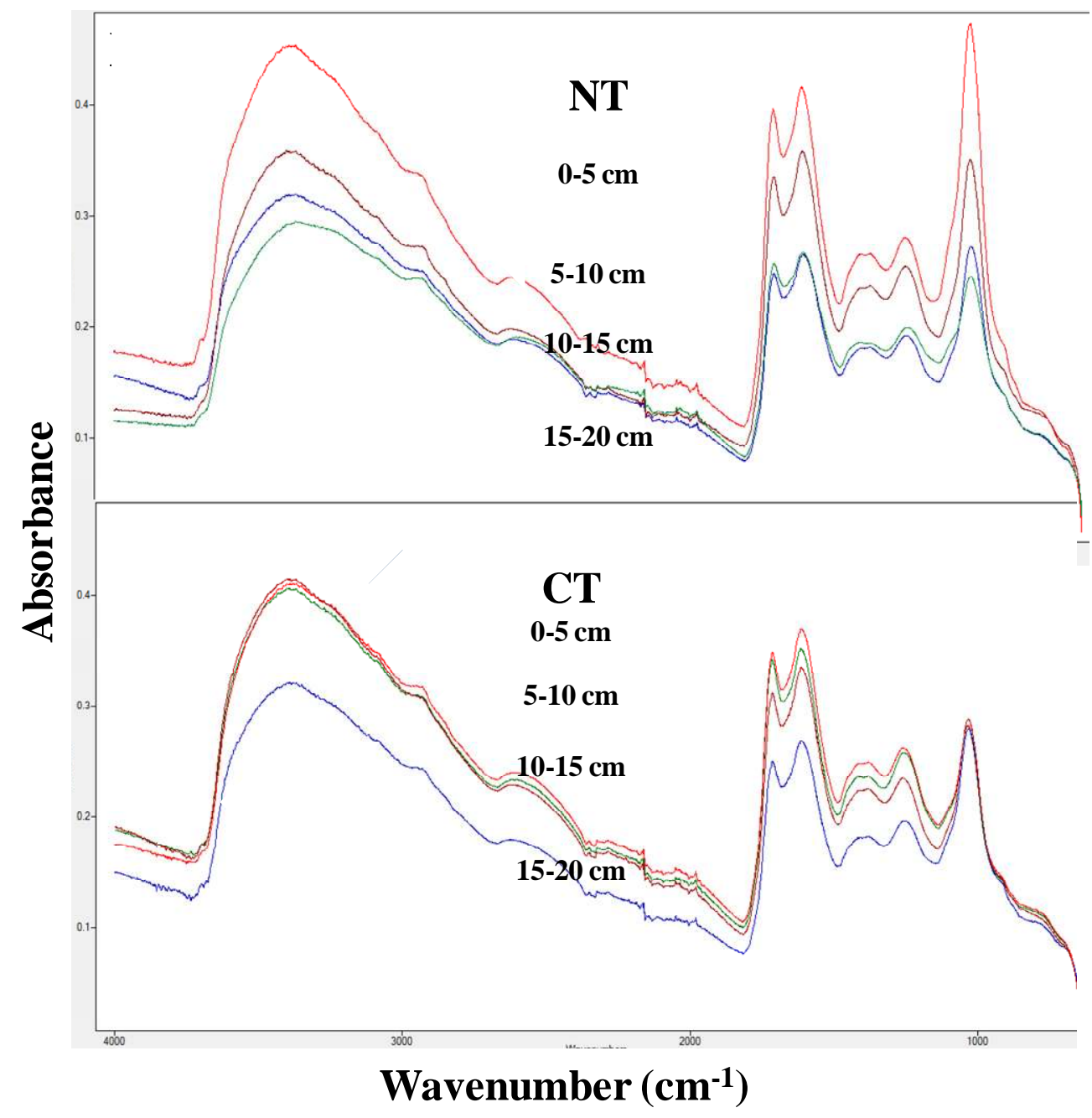

Fig. 2. FT-IR spectrum of humic acid extracted from different soil layers under conventional tillage (CT) and no-tillage (NT) systems
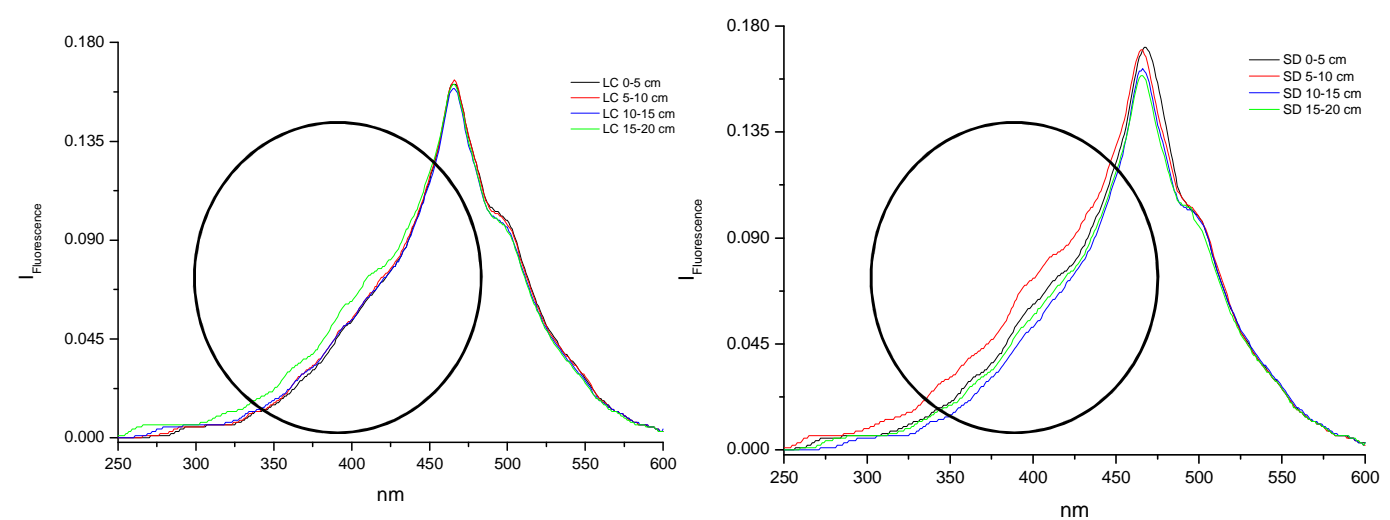

Fig. 3. Fluorescence spectrum of humic acid extracted from different soil layers under conventional tillage (CT) and no-tillage (NT) systems 


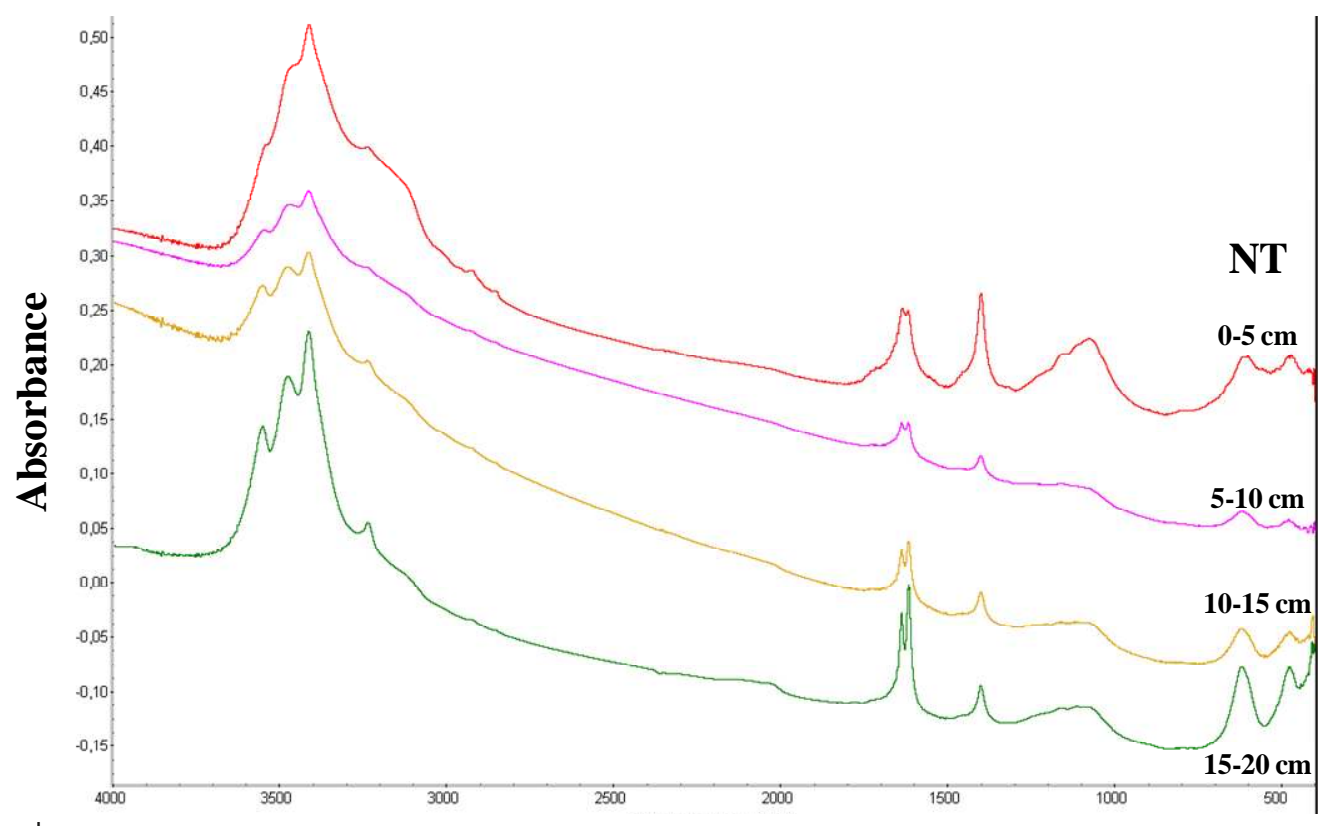

\section{Wavelenght $\left(\mathrm{cm}^{-1}\right)$}

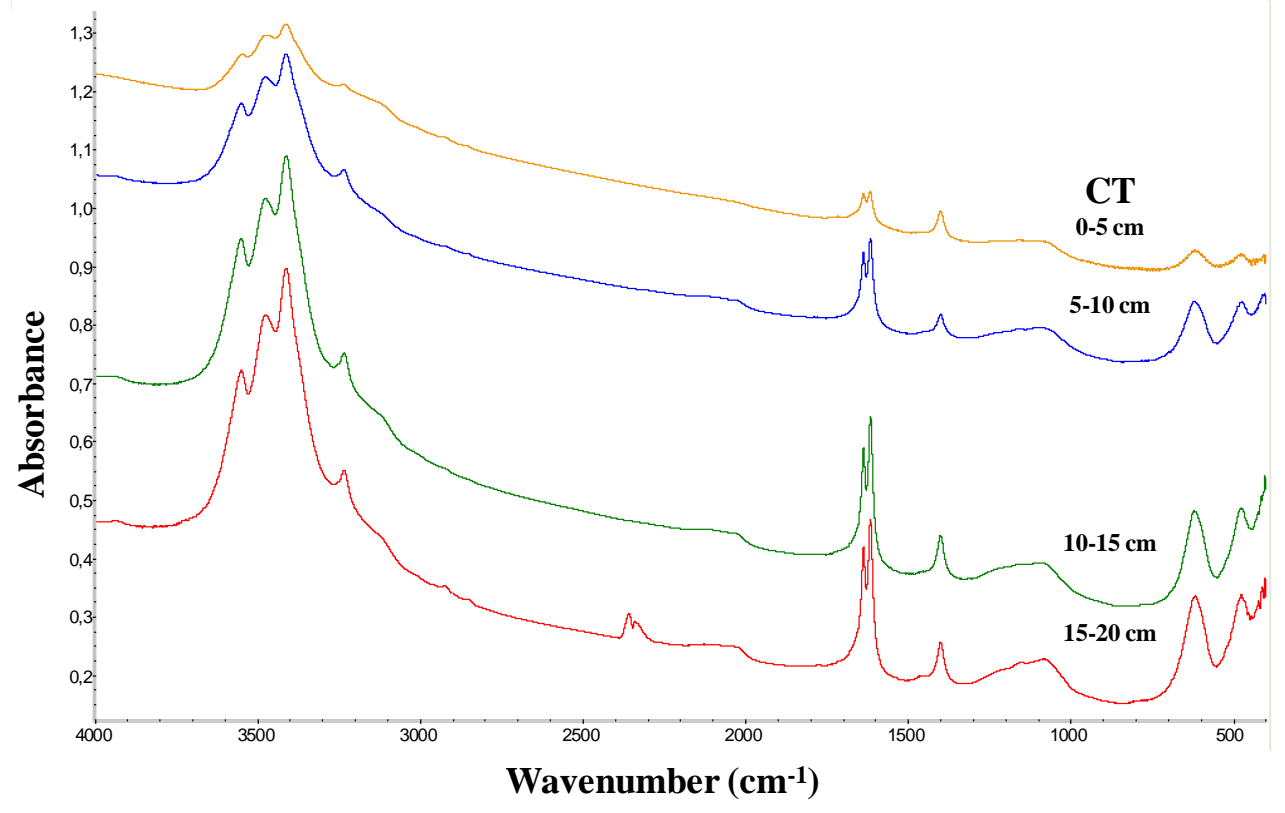

Fig. 4. FT-IR spectrum of fulvic acid extracted from different soil layers under conventional tillage (CT) and no-tillage (NT) systems

\section{CONCLUSION}

After 25 years under two tillage systems, total SOC at the $0-20 \mathrm{~cm}$ depth was $9 \%$ higher in notilled than in tilled soil. The POCf (53 to $105 \mu \mathrm{m})$ was the SOM fraction that turned out to be the most sensitive to tillage effects.
Residue cover (NT) and soil tillage mixing (CT) produced contrasting conditions for organic matter transformation and humification. The surface NT soil $(0-5 \mathrm{~cm})$ had highest $C$ input with better conditions for its transformation than deeper layer. Under CT, however, the tilled layer $(0-10$ to $0-15 \mathrm{~cm})$ presented similar residue input 
and condition for its transformation, which was slow down probably by its driest condition.

Soil tillage system produced different trends in the molecular functionality of HA fraction. The conventional tillage system showed higher molecular humification, starting by $\mathrm{CH}$ degradation, at more superficial soil depths. The no-tillage system, however, presented changes which are more difficult to interpret in the context of a simple humification process where microbial activity, oxygen availability, and/or labile carbon content are governed by soil depth. In fact, some results indicated that, apart from processes linked to SOM aerobic degradation, other relevant factors might be involved, mainly residue cover effect on SOM dynamics and humification across depths. Distribution of crop residues and soil moisture modified concentration of soil organic fractions as well as the characteristics of humic and, particularly, fulvic acids.

\section{ACKNOWLEDGEMENTS}

The authors wish to thank AAPRESID-Regional Bahía Blanca. We would also like to give special thanks to Hogar Funke, where the sampling was carried out, and to the BIOSPAS project (BID 1728 OC-AR 36976 PAE/PID 53).

\section{COMPETING INTERESTS}

Authors have declared that no competing interests exist.

\section{REFERENCES}

1. Bosatta E, Ågren GI. Theoretical analyses of soil texture effects on organic matter dynamics. Soil Biology and Biochemistry. 1997;29:1633-1638.

2. Kögel-Knabner I. Analytical approaches for characterizing soil organic matter. Organic Geochemistry. 2000;31:609-625.

3. Kleber M, Sollins P, Sutton R. A conceptual model of organo-mineral interactions in soils. Self-assembly of organic molecular fragments into zonal structures on mineral surfaces. Biogeochemistry. 2007;85:9-24.

DOI: 10.1007/s10533-007-9103-5

4. Sollins P, Swanston C, Kleber M. Organic $\mathrm{C}$ and $\mathrm{N}$ stabilization in a forest soil. Evidence from sequential density fractionation. Soil Biology and Biochemistry. 2006;38:3313-3324.
5. Lutzow M, Kogel-Knabner I, Ekschmitt K, Flessa H, Guggenberger G, Matzner M. SOM fractionation methods: Relevance to functional pools and to stabilization mechanisms. Review. Soil Biology \& Biochemistry. 2007;39:2183-2207. DOI: 10.1111/j.1365-2389.2006.00809.x

6. Cambardella CA, Elliott ET. Particulate soil organic-matter changes across a grassland cultivation sequence. Soil Science Society of American Journal. 1992;56:777-783.

7. Plaza $\mathrm{C}$, Courtier-Murias $\mathrm{D}$, Fernández JM, Polo A, Simpson AJ. Physical, chemical, and biochemical mechanisms of soil organic matter stabilization under conservation tillage systems. A central role for microbes and microbial by-products in $C$ sequestration. Soil Biology and Biochemistry. 2013;57:124-134.

8. Gregorich EG, Monreal CM, Carter MR, Angers DA, Ellert BH. Towards a minimum data set to assess soil organic matter quality in agricultural soils. Canadian Journal Soil Science. 1994;74:367-385.

9. $\mathrm{Xu} M$, Lou $Y$, Sun $X$, Wang $W$, Baniyamuddin $M$. Soil organic carbon active fractions as early indicators for total carbon change under straw incorporation. Biology and Fertility Soils. 2011;47:745752.

10. Schnitzer M, Khan SU. Humic Substances in the Environment. . Marcel Dekker, INC; 1972.

11. Hayes $M H$, MacCarthy $P$, Malcolm RL, Swift RS. Humic Substances. II: In Search of Structure; 1989.

12. Tan KH. Humic matter in soil and the environment. Principles and controversies; 2003.

13. Olk DC, Gregorich EG. Overview of the symposium proceedings, "meaningful pools in determining soil carbon and nitrogen dynamics". Soil Science Society of American Journal. 2006;70:967-974.

14. Christensen BT. Physical fractionation of soil and structural and functional complexity in organic matter turnover. European J. Soil Sci. 2001;52:345-353.

15. Galantini JA, Senesi N, Brunetti G, Rosell RA. Influence of texture on the nitrogen and sulphur status and organic matter quality and distribution in semiarid Pampean grassland soils. Geoderma. 2004;123:143-152.

16. Duval ME, Galantini JA, Iglesias JO, Canelo S, Martinez JM, Wall L. Analysis of 
organic fractions as indicators of soil quality under natural and cultivated systems. Soil \& Tillage Research. 2013;131:9-19.

17. Galantini JA, Duval ME, Iglesias JO, Kruger $\mathrm{H}$. Continuous wheat in semiarid regions: Long-term effects on stock and quality of soil organic carbon. Soil Science. 2014;179(6)284-292.

DOI: $10.1097 / S S .0000000000000072$

18. Chan KY, Heenan DP, Oates A. Soil carbon fractions and relationship to soil quality under different tillage and stubble management. Soil \& Tillage Research. 2002;63:133-139.

19. Halvorson AD, Peterson GA, Reule CA. Tillage system and crop rotation effects on dryland crop yields and soil carbon in the Central Great Plains. Agronomy Journal. 2002;94:1429-1436.

20. West TO, Post WM. Soil organic carbon sequestration rates by tillage and crop rotation. A global data analysis. Soil Science Society of American Journal. 2002;66:1930-1946.

21. Álvaro-Fuentes J, López MV, CanteroMartínez C, Arrúe JL. Tillage effects on soil organic carbon fractions in Mediterranean dryland agroecosystems. Soil Sci. Soc. Am. J. 2008;72:541-547.

22. Lal R. Soil carbon sequestration in Latin America. In: Lal R, Cerri CC, Bernoux M, Etcheves J, Cerri E. (Eds.). Carbon sequestration in soils of Latin America. Food Products Press, New York. 2006;4964.

23. Galantini JA, Iglesias JO, Maneiro C, Santiago L, Kleine C. Sistemas de labranza en el sudoeste bonaerense. Efectos de largo plazo sobre las fracciones orgánicas y el espacio poroso del suelo. Revista de Investigaciones Agropecuarias 2006;35:15-30. Spanish.

24. Bruce JP, Frome M, Haites E, Janzen H, Lal R, Paustian K. Carbon sequestration in soils. J. Soil Water Conserv. 1999;54:382389.

25. AAPRESID, Argentine No-Till Farming Association. Evolución de la superficie en Siembra Directa en Argentina; 2012. Access October 2015. Spanish. Available:http://www.aapresid.org.ar/wpcontent/uploads/2013/02/aapresid.evolucio $\underline{n}$ superficie sd argentina. 1977 a 2011.p df

26. Angers DA, Mehuys GR. Barley and alfalfa cropping effects on carbohydrate contents of a clay soil and its size fractions. Soil Biol. Biochem. 1990;22:285-288.

27. Puget $P$, Angers DA, Chenu C. Nature of carbohydrates associated with waterstable aggregates of two cultivated soils. Soil Biol. Biochem. 1999;31:55-63.

28. Elliott ET, Cambardella CA. Physical separation of soil organic matter. Agric. Ecosystems Environ. 1991;34:407-419.

29. Swift RS. Organic matter characterization. In D.L. Sparks et al. (eds) methods of soil analysis. Part 3. Chemical Methods. Soil Sci. Soc. Am. Book Series: 5. Soil Sci. Soc. Am. Madison, WI Capter 1996;35:1018-1020.

30. Baigorri R, Fuentes M, González-Gaitano G, García-Mina JM, Almendros G, González-Vila. Complementary multianalytical approach to study the distinctive structural features of the main humic fractions in solution. Gray humic acid, brown humic acid, and fulvic acid. J. Agric. Food Chem. 2009;57:3266-3272.

31. Chen Y, Senesi N, Schnitzer M. Information provided on humic substances by E4:E6 ratios. Soil Science Society of American Journal. 1977;41:352-358.

32. Zalba P, Gasparoni JC, Peinemann N. A rapid method for estimating the carbon concentration of fulvic acids. Communications in Soil Science and Plant Analysis. 1996;27:1-5.

33. Di Rienzo JA, Casanoves F, Balzarini MG, Gonzalez L, Tablada M, Robledo. InfoStat. Grupo InfoStat, FCA, Universidad Nacional de Córdoba, Argentina; 2010. Spanish.

34. Toledo DM, Galantini JA, Dalurzo HC, Vazquez S, Bollero G. Methods for assessing the effects of land-use changes on soil carbon stocks. Soil Science Society of American Journal. 2013;77:1542-1552.

35. Benbi DK, Brar K, Toor AS, Singh P. Total and labile pools of soil organic carbon in cultivated and undisturbed soils in northern India. Geoderma. 2015;237-238,149-158.

36. Singh J, Wu Q, McCool DK, Dun S, Lin C.$\mathrm{H}$, Morse. Winter hydrologic and erosion processes in the U.S. Palouse Region: Field experimentation and WEPP simulation. Vadose Zone J. 2009;8:426436.

37. Van Wie JB, Adam JC, Ullman JL. Conservation tillage in dryland agriculture impacts watershed hydrology. Journal Hydrology. 2013;483:26-38.

38. Balesdent J, Chenu C, Balabane M. Relationship of soil organic matter 
dynamics to physical protection and tillage. Soil \& Tillage Research. 2000;53:215-230.

39. Milori DM, Martin-Neto L, Bayer C, Mielniczuk J, Bagnato VS. Humification degree of soil humic acids determined by fluorescence spectroscopy. Soil Science. 2002;167:739-749.

40. Fuentes M, Baigorri R, Gonzalez-Gaitano G, Garcia-Mina JM. The complementary use of $1 \mathrm{H}$ NMR, $13 \mathrm{C}$ NMR, FTIR and size exclusion chromatography to investigate the principal structural changes associated with composting of organic materials with diverse origin. Organic Geochemistry. 2007;38:2012-2023.

41. Fuentes Ramírez M, González-Gaitano G, García-Mina JM. The usefulness of UV- visible and fluorescence spectroscopies to study the chemical nature of humic substances from soils and composts. Organic Geochemistry. 2006;37:19491959.

42. Kachari M, Belwar P, Dutta K, Sarmah A, Saikia PP, Baruah MK. Ultraviolet-visible and infrared spectroscopic studies of soil humic acids. International Journal of Plant \& Soil Science. 2015;6(4):194-202.

43. Peuravuori JR, Koivikko R, Pihlaja K. Characterization, differentiation and classification of aquatic humic matter separated with different sorbents. Synchronous scanning fluorescence spectroscopy. Water Research 2002;36:4552-4562.

(0) 2016 Galantini et al.; This is an Open Access article distributed under the terms of the Creative Commons Attribution License (http://creativecommons.org/licenses/by/4.0), which permits unrestricted use, distribution, and reproduction in any medium, provided the original work is properly cited.

Peer-review history:

The peer review history for this paper can be accessed here: http://sciencedomain.org/review-history/14142 